Revista da Faculdade de Direito-RFD-UERJ - Rio de Janeiro, n. 29, jun. 2016

\title{
DEMOCRACIA, PODER JUDICIÁRIO E RAZÃO PÚBLICA: UMA RELEITURA DO SUBSTANCIALISMO BRASILEIRO A PARTIR DE JOHN RAWLS
}

\author{
DEMOCRACY, JUDICIARY AND PUBLIC REASON: REREADING BRAZILIAN \\ SUBSTANCIALISM FROM JOHN RAWLS
}

Paulo Daniel Costa ${ }^{1}$

Carlos Alberto Esteves ${ }^{2}$

RESUMO: Em distintas realidades, a relação entre Direito e Política se fortalece, mas crescem os questionamentos sobre as possibilidades e os limites dessa relação. O substancialismo, corrente filosófica que surge nesse contexto, foi inserido no pensamento jurídico brasileiro com peculiaridades, a partir da adoção do modelo de democracia desenvolvido pelo filósofo liberal John Rawls. O presente trabalho busca revisitar esses pressupostos teóricos responsáveis pelo fortalecimento da atividade da jurisdição constitucional no Brasil, de modo a compreender os efeitos gerados no sistema político democrático. A partir de métodos de pesquisa dedutivos, combinados com técnicas bibliográficas, analisaram-se os principais elementos da teoria rawlsiana que contribuíram para o fortalecimento da teoria substancialista no Brasil. Posteriormente, com base em teorias recentes que estudam esse processo de judicialização da política passados mais de vinte anos do seu início, verificou-se que uma atuação excessiva do Poder Judiciário contribuiu para uma crise de diálogo entre as instituições estatais, o que evidencia a necessidade de se repensar as bases e o papel da jurisdição constitucional no sistema democrático.

PALAVRAS CHAVE: Razão Pública; Substancialismo; John Rawls; Jurisdição Constitucional.

\footnotetext{
${ }^{1}$ Bacharel em Direito pela Universidade Federal de Viçosa. Advogado Popular junto a Assessoria Jurídica Universitária Popular da UFV. E-mail: paulo_4cast@hotmail.com

${ }^{2}$ Mestrando em Ciências Políticas pela Universidade Federal de Minas Gerais. Professor Substituto de Direito Administrativo e de Direito Tributário junto ao Departamento de Direito da Universidade Federal de Viçosa. Advogado Popular junto a Assessoria Jurídica Universitária Popular da UFV. Bacharel em Direito pela Universidade Federal de Viçosa. E-mail: carlosestevesbf@yahoo.com.br
} 
ABSTRACT: In different realities, the relationship between Law and Politics becomes stronger, but questions rises about the possibilities and limits of this relation. The substancialism, as a philosophical current that arrises in this context, was inserted in Brazilian legal thought with certain peculiarities, adopting the democracy model developed by the liberal philosopher

John Rawls. This paper seeks to revisit these theoretical assumptions responsible for strengthening the constitutional jurisdiction activity in Brazil, in order to understand its causes and the effects generated in the democratic political system. Using deductive research methods, combined with bibliographical techniques, the main elements of Rawlsian theory that contributed to the strengthening of substantial theory in Brazil were analyzed. Subsequently, based on recent theories that study the process of judicialization of politics after more than twenty years, it is demonstrated that an excessive performance of the judiciary contributed to a dialog crisis between the state institutions. This highlights the need to rethink the foundations and the role of constitutional jurisdiction in the democratic system.

KEY-WORDS: Public Reason; Substancialism; John Rawls; Constitutional Jurisdiction.

\section{INTRODUÇÃO}

O debate sobre a judicialização da política, crucial para a definição do papel da jurisdição constitucional, perpassa pela forma como cada sistema filosófico-político entende a democracia e a relação desta com a efetividade da Constituição, enquanto diploma normativo que possui força política. A temática, que divide literaturas, merece atenção científica por se tratar, em outras palavras, de identificar a relação existente entre Direito e Política, convívio este que, por se fortalecer constantemente, está em questionamento.

Desde a promulgação da Constituição brasileira de 1988, vivencia-se uma cadeia de transformações jurídicas e políticas marcadas pela consolidação do constitucionalismo democrático, o qual transformou os antigos paradigmas de ética e de justiça predominantes no modelo positivista. $\mathrm{O}$ constitucionalismo liberal, que protegia de forma limitada os direitos pertinentes à liberdade, é substituído pelo constitucionalismo social, pautado pela ampliação das obrigações do Estado em termos de garantia de direitos sociais, econômicos e culturais. 


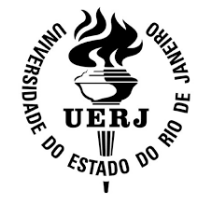

De tal forma, e também como decorrência do fortalecimento das Teorias do Direito Crítico, os direitos sociais ganharam atenção no cenário jurídico nacional. Da constatação doutrinária de que existem muitas garantias sociais a serem efetivadas e frente a uma crise de representatividade do Poder Legislativo, o Poder Judiciário passou a ser chamado para atuar na proteção desses direitos. A legitimidade democrática da jurisdição constitucional tem sido questionada, especialmente no contexto brasileiro, onde ela tem se destacado como excessivamente ativista.

De fato, muitas vezes a atuação do Poder Judiciário tem assumido posição de destaque na dinâmica política nacional. Isso porque a função jurisdicional tem, de certa forma, efetuado intenso controle sobre as atividades dos representantes legislativos e executivos, os quais são escolhidos, por intermédio de processo eleitoral, diretamente pela população. Caso emblemático e que ilustra essa crise institucional é a decisão, em caráter liminar, do ministro do Supremo Tribunal Federal (STF) Gilmar Mendes no Mandado de Segurança (MS) 32.033, impetrado pelo Senador Rodrigo Rollemberg (PSB-DF). O ministro decidiu suspender a tramitação do Projeto de Lei Complementar 14/2013, afirmando, dentre outros pontos, que houve aparente tentativa de mudança das regras de formação de partidos em prejuízo às minorias políticas e à própria democracia.

A decisão, apresentada com intuito exemplificativo, não foi bem recebida por membros do Poder Legislativo, o que se verifica a partir dos relatórios legislativos apresentados no decorrer das discussões do Projeto de Emenda Constitucional $\mathrm{n}^{\mathbf{o}} 33$, de $2011^{3}$. As reações deixam claro o fato de que há um acirramento e um desgaste entre os Poderes da República. Curioso observar que há um recorrente argumento utilizado pelo Poder Judiciário para fundamentar sua atividade de controle: a integridade do sistema democrático.

Nesse contexto, as Teorias da Democracia e da Constituição passam por um momento de crise. Tanto os modelos formais-procedimentais como os paradigmas materiais-dirigistas estão sendo revistos à luz de variados elementos que transpiram da experiência institucional das últimas décadas. De tal modo, o que em épocas de normativismo puro era inimaginável,

\footnotetext{
${ }^{3}$ A proposta, arquivada em 2015, pretendia alterar a quantidade mínima de votos de membros de tribunais para declaração de inconstitucionalidade de leis; condicionar o efeito vinculante de súmulas aprovadas pelo Supremo Tribunal Federal à aprovação pelo Poder Legislativo; e submeter ao Congresso Nacional a decisão sobre a inconstitucionalidade de emendas à Constituição.
} 
agora Direito e Política se relacionam, procurando interligar pressupostos de um Estado Constitucional com paradigmas de um Estado Democrático. Todavia, esse convívio é alvo de muitas críticas, o que provocou questionamentos a pensamentos, outrora consolidados, de Teoria da Democracia e de Teoria da Constituição. Revisitar essas teorias, à luz de outras matrizes, faz-se necessário, na tentativa de compreender o que se tem de experiência e vivência no atual contexto juspolítico.

É possível verificar que o pensamento jurídico brasileiro se baseou no modelo de justiça política liberal de John Rawls para construir e fundamentar a legitimidade da atuação do Poder Judiciário no controle de atividades de natureza política. O presente trabalho busca revisitar os esses pressupostos teóricos responsáveis pelo fortalecimento da atividade da jurisdição constitucional em terras brasileiras, o que faz com base em teorias recentes que analisam esse processo de judicialização passados mais de vinte anos do seu início.

Para tanto, a presente proposta investigativa, em termos metodológicos, realiza uma pesquisa teórica, com perfil exploratório, mediante o uso do método de pesquisa dedutivo e da técnica de pesquisa bibliográfica. O método é dedutivo porque, a partir da análise dos principais elementos da Teoria de Justiça política de John Rawls, uma teoria que se apresenta abrangente em termos teóricos, realiza-se um estudo das atividades da jurisdição constitucional no Brasil.

Diante disso, nos primeiros dois capítulos, faz-se uma análise expositiva dos principais elementos da teoria Rawlsiana. Primeiramente, expõe-se a Teoria de Justiça como Equidade, demonstrando como são construídos, no âmbito do sistema democrático de Rawls, os princípios políticos de justiça formadores de uma comunidade. A construção desses princípios é justificada discursivamente em um momento deliberativo apriorístico, no qual são definidas as bases da razão pública.

No segundo capítulo, analisa-se a construção dessa razão pública e sua importância na definição da legitimidade democrática da jurisdição constitucional, legitimidade essa que estaria assentada na ideia da formação de um consenso sobreposto. No terceiro capítulo, apontam-se as características especiais da adoção do modelo substancialista rawlsiano no Brasil, a partir das quais é possível analisar os efeitos ocasionados no sistema político a partir 
da incorporação de um modelo ativista de jurisdição constitucional, evidenciando-se os limites desse modelo na construção de uma relação fortalecida entre Direito e Política.

\title{
1 A TEORIA DE JOHN RAWLS: JUSTIÇA COMO EQUIDADE
}

O pensador americano John Rawls desenvolveu uma Teoria da Justiça que permite sustentar a fundamentalidade de alguns direitos ligados à pessoa humana, tanto individualmente, como em sua vida em comunidade. Rawls elabora sua Teoria da Justiça como Equidade utilizando-se do construtivismo político para aliar a perspectiva moral de justiça à perspectiva jurídica. Afasta as influências do intuicionismo ${ }^{4}$ e do construtivismo moral kantiano ${ }^{5}$, para defender que a construção de um acordo sobre os termos equitativos de uma sociedade é baseado no construtivismo político, segundo o qual "os princípios de justiça política (o conteúdo) podem ser representados como o resultado de um certo procedimento de construção (a estrutura)" (RAWLS, 2000b, p. 134).

\begin{abstract}
Nesse procedimento, modelado de acordo com a posição original, os agentes racionais, enquanto representantes dos cidadãos e sujeitos a condições razoáveis, selecionam os princípios públicos de justiça que devem regular a estrutura básica da sociedade (RAWLS, 2000b, p. 134).
\end{abstract}

Tais premissas constituem princípios de justiça que devem ser institucionalizados e aplicados nas estruturas diversas de uma sociedade bem organizada ${ }^{6}$. John Rawls defende uma concepção de democracia deliberativa baseada na predefinição de Princípios de Justiça e na igualdade social a partir de um contexto inicial, pré-constitutivo à ordem jurídica. Segundo

\footnotetext{
${ }^{4}$ Intuicionismo é a doutrina segunda a qual há "um conjunto irredutível de princípios básicos que devemos pesar e comparar perguntando-nos qual equilíbrio, em nosso entendimento mais refletido, é o mais justo" (RAWLS, 2000a, p. 37).

5 “(...) a doutrina de Kant é uma visão moral abrangente em que o ideal autonomia tem um papel regulador para tudo na vida. Isso o torna incompatível com o liberalismo político da justiça como equidade. Um liberalismo abrangente baseado no ideal de autonomia pode, evidentemente, fazer parte de um consenso sobreposto razoável que endosse uma concepção política; mas, como tal, não é apropriado para fornecer uma base pública de justificação." (RAWLS, 2000b, p. 144).

${ }^{6}$ Para Rawls, uma sociedade é bem-ordenada "não apenas quando está planejada para promover o bem de seus membros, mas quando é também efetivamente regulada por uma concepção pública de justiça. Isto é, trata-se de uma sociedade na qual (1) todos aceitam e sabem que os outros aceitam os mesmos princípios de justiça, e (2) as instituições sociais básicas geralmente satisfazem, e geralmente se sabe que satisfazem, esses princípios. (...) Pode-se imaginar uma concepção da justiça como constituindo a carta fundamental de uma associação humana bem-ordenada. Sociedades concretas são, é óbvio, raramente bem ordenadas nesse sentido, pois o que é justo e o que é injusto está geralmente sob disputa." (RAWLS, 2000a, p. 5).
} 
Rawls, existiria uma posição original ${ }^{7}$, vale dizer, uma situação política primitiva a partir da qual haveria um acordo sobre os princípios norteadores da sociedade em construção.

Para escolher esses Princípios de Justiça e obter um consenso sobre eles, os indivíduos dessa comunidade - em pé de igualdade e sob o véu da ignorância ${ }^{8}$ - fariam juízos de ponderação para que busquem o bem-comum de acordo com suas convicções comuns. $\mathrm{O}$ acordo obtido em tal situação fixaria direitos e deveres fundamentais dos indivíduos e das instituições sociais, obedecendo sempre a dois princípios: o da igual liberdade; e o da desigualdade, desde que seja esta um subcaso da igualdade, ou seja, desde que a desigualdade traga vantagens para todos (RAWLS, 2000a, p. 66).

A concepção de justiça rawlsiana está baseada em um sistema de prioridades de princípios. O pensador apresenta, como problema motor, a concepção política de justiça frente à pluralidade de doutrinas filosóficas, religiosas e morais razoáveis defendidas nas sociedades modernas $^{9}$ e, como premissa investigatória, a coexistência de cidadãos livres e iguais. Constrói um sistema de prioridade principiológica, que deve ser visto como diretriz da forma pela qual as instituições devem realizar os valores da liberdade e da igualdade (RAWLS, 2000b, p. 47 $)^{10}$.

\footnotetext{
7 “A posição original é definida de modo a ser um status quo no qual as partes são igualmente representadas como pessoas dignas, e o resultado não é condicionado por contingências arbitrárias ou pelo equilíbrio relativo das forças sociais. (...) Fica claro, então, que a posição original é uma situação puramente hipotética.” (RAWLS, 2000a, p. 129-30).

8 "A ideia da posição original é estabelecer um processo equitativo, de modo que quaisquer princípios aceitos sejam justos. O objetivo é usar a noção de justiça procedimental pura como fundamento da teoria. De algum modo, devemos anular os efeitos das contingências específicas que colocam os homens em posição de disputa, tentando-os a explorar as circunstâncias naturais e sociais em seu próprio benefício. Com esse propósito, assumo que as partes se situam através de um véu de ignorância. Elas não sabem como as várias alternativas irão afetar o seu caso particular, e são obrigadas a avaliar os princípio (sic) unicamente com base nas considerações gerais". (RAWLS, 2000a, p. 146-147).

9 John Rawls parte do pluralismo político para construir sua teoria da democracia. Mas não somente: "A gravidade do problema [construção de uma doutrina política abrangente racional] reside no fato de que uma sociedade democrática moderna não se caracteriza apenas por um pluralismo de doutrinas religiosas, filosóficas e morais abrangentes. Nenhuma dessas doutrinas é professada pelos cidadãos em geral. Nem se deve esperar que, num futuro previsível, uma ou outra doutrina razoável chegue a ser professada algum dia por todos os cidadãos, ou por quase todos. O liberalismo político pressupõe que, para propósitos políticos, uma pluralidade de doutrinas abrangentes e razoáveis, e, ainda assim, incompatíveis, seja o resultado normal do exercício da razão humana dentro da estrutura das instituições livres de um regime democrático constitucional. (...) Dado o pluralismo razoável da cultura democrática, o objetivo do liberalismo político consiste em descobrir em que condições é possível haver uma base de justificação pública razoável no tocante a questões políticas fundamentais." (RAWLS, 2000b, p. 24-27).

${ }^{10}$ Descreve o sistema de prioridades de princípios da seguinte maneira: "Primeiro princípio - Todas as pessoas têm igual direito a um projeto inteiramente satisfatório de direitos e liberdades básicas iguais para todos, projeto esse compatível com todos os demais; e, nesse projeto, as liberdades políticas, e somente estas, deverão ter seu valor equitativo garantido. Segundo princípio - As desigualdades sociais e econômicas devem satisfazer dois requisitos: primeiro, devem estar vinculadas a posições e cargos abertos a todos, em condições de igualdade
} 
Em seu sistema, Rawls apresenta como o primeiro princípio na escala de prioridades o da igual liberdade. Para ele, "todas as pessoas têm igual direito a um projeto inteiramente satisfatório de direitos e liberdades básicas iguais para todos, projeto esse compatível com todos os demais" (RAWLS, 2000b, p. 47). Nesse trecho, o estudioso desenvolve a ideia de que as pessoas são livres para determinar seus projetos de vida, de felicidade, de bem, desde que esses projetos respeitem a igual liberdade dos demais cidadãos de desenvolver seus planos. Como liberalista que é, afirma que a única liberdade que tem valor equitativo garantido entre os agentes de uma mesma comunidade é a liberdade política.

Já as liberdades econômicas e sociais não têm valor equitativo garantido. Isso porque Rawls compreende, já passando para o segundo princípio no seu sistema de prioridades, que desigualdades sociais e econômicas não implicam, necessariamente, em injustiça. O pensador aponta que para que as desigualdades possam existir, dois requisitos devem ser satisfeitos: "primeiro, devem estar vinculadas a posições e cargos abertos a todos, em condições de igualdade equitativa de oportunidades; e, segundo, devem representar o maior benefício possível aos membros menos privilegiados da sociedade" (RAWLS, 2000b, p. 47).

Esses princípios são vistos por Rawls como "manifestações do conteúdo de uma concepção política liberal de justiça” (RAWLS, 2000b, p. 48). Apesar de denominar sua teoria da justiça de Justiça como Equidade ${ }^{11}$, não é difícil observar que o conceito de liberdade está no centro da sua teoria, inclusive como primeiro princípio em sua escala de prioridades. A igualdade defendida por Rawls é a igualdade política, construindo uma filosofia do sujeito diferenciada, traçando o conceito de pessoa como ser político, distanciando-se da tradição kantiana do eu como ser moral (RODAS et al, 1996, p. 12).

Todavia, é importante ter em mente que a concepção de pessoa que Rawls apresenta faz parte de uma concepção política da justiça, cujo papel é distinto daquele que uma concepção de pessoa possa exercer como um ideal pessoal ou associativo, ou em um modo de vida moral ou religioso em particular. (OLIVEIRA, 2010, p. 88)

equitativa de oportunidades; e, segundo, devem representar o maior benefício possível aos membros menos privilegiados da sociedade." (RAWLS, 2000b, p. 47).

${ }^{11} \mathrm{Na}$ versão original, o autor utiliza a palavra fairness. Alguns autores brasileiros ressaltam que, a rigor, tal termo não significa equidade: "Traduzo o termo inglês "fairness" por equanimidade e não por eqüidade, para marcar o contexto não- aristotélico da Teoria da Justiça apresentada por John Rawls, uma concepção que se pretende procedimental e não substantivista". (OLIVEIRA, 2003, p. 26). 
Nesse objetivo conceitual, Rawls afirma que os cidadãos são concebidos como indivíduos que se julgam livres em três aspectos, sendo que, a partir da análise desses elementos, demonstra de que forma a concepção de pessoa é política (eu-político) ${ }^{12}$. Apesar disso, Rawls defende a intangibilidade dos valores comuns e consensos abrangentes pelos interesses de grupos políticos majoritários ocasionais. A proteção desses termos equitativos e do consenso sobreposto é função do Poder Judiciário.

Ao aplicar a razão pública, o tribunal deve evitar que a lei seja corroída pela legislação de maiorias transitórias ou, mais provavelmente, por interesses estreitos, organizados e bem-posicionados, muito hábeis na obtenção do que querem. (RAWLS, 2000b, p. 284).

Justifica isso pela ideia de mínimo social: a garantia de que cada homem disponha de um conjunto mínimo de bens primários sem os quais o acordo obtido na posição original não seria equitativo (RAWLS, 2000b, p. 225-26). O mínimo social é o pressuposto fático que permite a construção dessa sociedade democrática baseada na igualdade dos indivíduos.

\section{RAZÃo PÚbliCA E PODER JUDICIÁRIO NA TEORIA DA DEMOCRACIA DE RAWLS}

A deliberação, resgatando o que já foi comentado sobre a teoria política rawlsiana, consiste em um processo de aplicação de Princípios de Justiça. Tais princípios estariam a salvo das decisões tomadas majoritariamente, de maneira que, quando não estão em pauta dialógica questões políticas fundamentais, as maiorias podem decidir conforme as doutrinas razoáveis e socialmente abrangentes, e não de acordo com a razão pública. Por ora, dois conceitos carecem de esclarecimento: (a) doutrinas abrangentes e razoáveis e (b) razão pública.

Doutrinas abrangentes e razoáveis se caracterizam por conterem três traços essenciais. Primeiramente, a doutrina razoável é fruto do exercício da razão teórica, o que significa que aspectos filosóficos, religiosos e morais da vida humana organizam valores reconhecidos de modo que sejam compatíveis entre si e expressam uma visão de mundo que seja inteligível (RAWLS, 2000b, p. 103). Esses valores, que caracterizam as doutrinas como abrangentes,

\footnotetext{
${ }^{12}$ Não serão analisados esses aspectos, por serem de conteúdo que extrapolam os objetivos do presente trabalho. Para aprofundamento: RAWLS, 2000b.
} 
passarão por um processo de seleção ${ }^{13}$, de modo que distinga as doutrinas umas das outras, cada uma atribuindo um peso especial para determinado feixe de valores. Essa característica representa o exercício da razão prática. Por último, a terceira característica revela que uma doutrina razoável é estável, mas não é imutável; está em lento processo de evolução, diante das justificações e contextos que exsurgem do meio social e que influem na percepção dos valores pelas pessoas (RAWLS, 2000b, p. 103).

A razão pública em Ralws está relacionada ao modo como o pensador constrói sua concepção política de justiça ${ }^{14}$. No momento em que Rawls define sua concepção de deliberação pública como processo de aplicação de princípios de justiça, lança a ideia da razão pública. Para ele,

a razão pública é aquela que caracteriza a argumentação política que tem lugar em uma democracia constitucional bem ordenada, e o seu objeto é o bem público, entendido como o que se pode esperar legitimamente da estrutura básica da sociedade. (SOUZA NETO, 2006, p. 112).

Rawls afirma que há razões públicas e não-públicas. As públicas podem ser identificadas por três elementos: primeiro, é a razão utilizada pelos cidadãos no exercício de seus direitos e deveres políticos (admite também a utilização da razão pública pelo Estado, o que será explicado à frente); segundo, seu objeto é o bem público e as questões de justiça fundamental; terceiro, sua natureza e seu conteúdo são determinado pelos ideais e princípios que compõem a concepção política de justiça da sociedade (RAWLS, 2000b, p. 262).

À primeira vista, o que se observa é que a razão pública requer uma dimensão material, isto é, tem um conteúdo definido, no sentido de que os discursos devem ser justificadores dos princípios de justiça. Os limites impostos pela razão pública não são extensíveis a todas as questões políticas, mas tão somente àquelas que Rawls chama de "elementos constitucionais essenciais e questões de justiça básica" (RAWLS, 2000B, p. 263). São as deliberações cujo conteúdo envolve aspectos de princípios de justiça, nas quais os

13 "A partir de trabalhos posteriores à obra A Theory of Justice, a teoria de John Rawls tem procurado tornar- se o que esse filósofo norte - americano chama de "Construtivismo Político" ("Polítical Constructivism ") em que a linguagem do contratualismo ressurge como estratégia de exposição, a fim de explicar, através da idéia de "posição original" ("original position"), que como um todo é um "mecanismo de representação" ("device of representation") dos cidadãos livres e iguais em uma sociedade bem ordenada como os princípios da justiça podem ser selecionados e não escolhidos pelas "partes"." (OLIVEIRA, 2010, p. 27). [grifo no original].

14 "A razão pública é característica de um povo democrático: é a razão de seus cidadãos, daqueles que compartilham o status da cidadania igual. O objeto dessa razão é o bem do público: aquilo que a concepção de justiça requer da estrutura básica das instituições da sociedade dos objetivos e fins a que devem servir." (RAWLS, 2000b, p. 261-62). 
discursos deverão superar a defesa de doutrinas abrangentes, limitando-se ao uso da razão pública.

Além disso, ao mencionar que o conteúdo da razão pública é a concepção política de justiça, o pensador americano realiza três reflexões:

\begin{abstract}
A primeira é que esse conteúdo especifica certos direitos, liberdades e oportunidades fundamentais (do tipo que conhecemos nos regimes democráticos); a segunda é que atribui uma prioridade especial a esses direitos, liberdades e oportunidades, principalmente no que diz respeito às exigências do bem geral e de valores perfeccionistas; e a terceira é que esse conteúdo endossa medidas que garantem a todos os cidadãos os meios polivalentes adequados para tornar efetivo o uso de suas liberdades e oportunidades básicas. (RAWLS, 2000b, p. 272-73).
\end{abstract}

Uma concepção de justiça é política na medida em que: (a) é articulada para ser aplicada às principais instituições sociais, políticas e econômicas de uma sociedade; (b) sua legitimidade é independente e prévia a qualquer doutrina abrangente e razoável; (c) e que é elaborada para constituir "ideias políticas fundamentais, vistas como ideias implícitas na cultura política e pública de uma sociedade democrática" (RAWLS, 2000b, p. 273).

Desse modo, fica claro que, para Rawls, a razão pública tem a função de atribuir justificação aos princípios substantivos de justiça, de modo a garantir que sejam aplicados corretamente. Para tanto, imagina diretrizes de indagação que funcionam como elementos argumentativos para a elaboração de justificações atinentes às questões políticas. São as diretrizes: "princípios de argumentação e regras de evidências à luz das quais os cidadãos devem julgar se os princípios substantivos aplicam-se de forma apropriada e identificar as leis e políticas que melhor os satisfaçam" (RAWLS, 2000b, p. 273).

Delineados esses conceitos, pode-se trabalhar o papel da jurisdição constitucional em uma democracia deliberativa substantiva. Rawls define a existência de uma dupla função à jurisdição constitucional: defesa das opções políticas fundamentais e fomento ao uso da razão pública.

Rawls afirma que, em uma democracia com controle de constitucionalidade, "a razão pública é a razão do supremo tribunal" (RAWLS, 2000b, p. 281), sendo que o tribunal, ao aplicar a razão pública, “deve evitar que a lei seja corroída pela legislação de maiorias transitórias ou por interesses estreitos" (RAWLS, 2000b, p. 284). 
lei ordinária, pois um tribunal com poderes de revisão judicial pode declarar tal lei inconstitucional. Não obstante, a autoridade superior do povo dá sustentação a isso. O tribunal é antimajoritário com respeito à lei mais alta quando suas decisões estão razoavelmente de acordo com a constituição em si, com as emendas feitas a ela e com as interpretações politicamente determinadas. (RAWLS, 2000b, p. 284).

As cortes constitucionais assumem o papel de intérpretes supremos da constituição. Para exercer essa atividade hermenêutica, Rawls demarca um limite muito claro para a atividade jurisdicional: o uso único e exclusivo da razão pública. Isso significa que os fundamentos para a interpretação jurisdicional da constituição podem ser encontrados na razão pública, que, por sua vez, é composta pelas concepções políticas de justiça fundamentais. Sendo assim, a atividade da jurisdição constitucional nada mais é do que zelar e expandir por todo o ordenamento os princípios de justiça, assim por dizer, os elementos constitucionais essenciais, dentre os quais se situam os direitos fundamentais.

A legitimidade democrática da jurisdição constitucional se assenta na regra de que o Poder Judiciário deve exercer unicamente a razão pública. Segundo Rawls, os cidadãos e os legisladores podem defender e agir conforme suas doutrinas particulares razoáveis, quando os princípios de justiça não representarem obstáculo à ação. Os juízes, por sua vez, só podem se servir do uso público da razão, pois foram criados para justificar, garantir a melhor interpretação à lei maior, dar consistência a suas razões e "articulá-las numa visão constitucional coerente" (RAWLS, 2000b, p. 286).

Aqui, a melhor interpretação é aquela que melhor se articula com o corpo pertinente daqueles materiais constitucionais, e que se justifica nos termos da concepção pública de justiça ou de uma de suas variantes razoáveis. (RAWLS, 2000b, p. 286).

Tal função de defesa dos elementos fundamentais dá ensejo à segunda função da atividade da jurisdição constitucional: fomentar o uso da razão pública. Espera-se dos juízes que, ao utilizar-se da razão pública, possam enaltecer os valores políticos da concepção pública, sempre que a constituição arrole esses valores. Assume, assim, papel de dar publicidade à razão, transpassando uma postura educativa.

As posturas que, de um modo ou de outro, trabalham com essa perspectiva [substancialista], partem da perspectiva de que a função da jurisdição constitucional deve fazer prevalecer a Constituição contra as maiorias eventuais. Cabe sublinhar, aqui, o dizer de Korineck, para quem "a vinculação do legislador às determinações constitucionais é ao mesmo tempo a vinculação do legislador democraticamente legitimado a um ato de mais elevada legitimação democrática”. (STRECK, 2002, p. 141-42). 
Encerrando a visão de Rawls e trabalhando com a matéria sob uma perspectiva mais geral, tem-se que o modelo substancialista advoga a perspectiva segundo a qual a Constituição estabelece as opções políticas fundamentais, vinculando o agir político-estatal conforme essas previsões. Nesse passo, o papel da jurisdição constitucional é proteger as disposições constitucionais fundamentais, o que faz a partir de um procedimento discursivo embasado na utilização da razão pública, da qual se retira a legitimidade democrática de sua atuação.

\section{SUBSTANCIALISMO BRASILEIRO E O SISTEMA DEMOCRÁTICO DE JOHN RAWLS}

Uma discussão importante para a identificação do papel da jurisdição constitucional perpassa pela forma como diferentes correntes de pensamento visualizam o próprio significado de democracia e a relação desta com a efetividade da Constituição. De um lado, encontram-se os substancialistas, que assumem a defesa contramajoritária, a partir da proteção das disposições constitucionais essenciais pela atividade jurisdicional ${ }^{15}$. De outro, os procedimentalistas afirmam a falta de legitimidade do Poder Judiciário para atuar na proteção às disposições constitucionais fundamentais, pois tal atuação desfortalece a política enquanto espaço de exercício de direitos ${ }^{16}$.

Divergem os teóricos deliberativos sobre o papel da atividade jurisdicional nesse modelo de democracia, no que diz respeito às atribuições e à natureza do Poder Judiciário, especialmente da Corte responsável pela jurisdição constitucional. Suas funções consistem em proteger os projetos constitucionais fundamentais em face da vontade das maiorias ocasionais, assumindo natureza política; ou garantir tão somente as regras do jogo democrático, avocando natureza puramente jurídica.

\footnotetext{
15 "Especialmente nesse eixo, valorize-se o juiz como personagem de uma intelligentsia especializada em declarar como direito princípios já admitidos socialmente - vale dizer, não arbitrários - e como intérprete do justo na prática social”. (VIANNA et al, 1999. p. 24).

16 "Desse eixo viria a compreensão de que a invasão da política pelo direito, mesmo que reclamada em nome da igualdade, levaria à perda da liberdade, 'ao gozo passivo de direito', 'à privatização da cidadania', ao paternalismo estatal, na caracterização de Habermas, e, na de Garapon, 'à clericialização da burocracia', 'a uma justiça de salvação', com a redução dos cidadãos ao estatuto de indivíduos-clientes de um Estado providencial”. (VIANNA et al, 1999, p. 23-24).
} 
O ponto fulcral na divergência entre procedimentalistas e substancialistas é a admissão, por parte destes, da técnica da ponderação de valores como uma prática legítima de operação jurídica. Para aqueles, a concretização das normas jurídicas por uma técnica valorativa desrespeita não só a democracia, mas ameaça o pluralismo, visto que o juiz estaria impondo uma determinada forma de se ver a vida em detrimento de outras doutrinas igualmente razoáveis.

Desse modo, o procedimentalismo procura destacar não o erro no emprego das técnicas ligadas às teorias da argumentação, mas essencialmente a equivocidade em si das mesmas, tanto do ponto de vista político-sociológico ao colocar em risco a própria democracia, eis que o juiz passa a se arrogar à condição de legislador, como do ponto de vista científico, eis que lastreado em um método - a lei da colisão vista por muitos como verdadeiro postulado normativo ou marca do paradigma contemporâneo - a proporcionalidade. (CRUZ, 2009, p. 18).

No contexto brasileiro, o substancialismo obteve um maior número de adeptos por parte de juristas. Nomes do direito constitucional contemporâneo, como Luís Roberto Barroso (BARROSO, 2010, p. 92) e Lênio Luis Streck (STRECK, 2002, p. 81), afirmam claramente sua opinião a favor da tese substancialista. Em função dessa ampla adesão, o sistema de justiça brasileiro incorporou muitas bases dessa linha de pensamento, principalmente do modelo rawlsiano de liberalismo político.

Essa incorporação do substancialismo no sistema de justiça do Brasil apresentou fundamentos próprios e gerou consequências peculiares no território nacional. Apesar disso, é possível afirmar que esse movimento utilizou como base principal a Teoria de Justiça política de Rawls, especialmente no que toca o dever de o Poder Judiciário proteger os Princípios de Justiça fundamentais, expressos através das disposições constitucionais.

Ao incorporar teorias substancialistas no sistema jurídico nacional, o Poder Judiciário utiliza-se do conceito de razão pública, conforme definido por John Rawls, para fundamentar sua interferência em cenários políticos. Essa razão pública é imparcial às diferentes linhas de pensamento, não se confundindo com julgamentos políticos, pois está baseada, em última instância, nas opções políticas formadoras de um consenso sobreposto, acima das vontades ocasionais de outras doutrinas razoáveis abrangentes. O substancialismo encontra no desenvolvimento da ideia de razão pública sua principal guarida para justificar a legitimidade democrática da jurisdição constitucional. 
Contudo, uma leitura normativista das Teorias da Justiça e da Teoria da Democracia não deve dispensar uma interpretação realista das instituições. Por isso, é necessário investigar o que realmente envolve a incorporação de um liberalismo político nos moldes rawlsianos no sistema de justiça brasileiro.

O elemento central responsável por essa incorporação do substancialismo no sistema brasileiro advém de uma desconfiança no desenvolvimento institucional de políticas sociais. A principal justificativa é a constatação de que os direitos sociais, no contexto nacional, carecem de proteção por parte dos outros Poderes do Estado. O alinhamento de grande parte da doutrina brasileira ao substancialismo se dá, desse modo, em atenção aos direitos sociais, por entender que esses direitos devem fazer parte da agenda de todos os Poderes.

É o que defende o professor Streck (STRECK, 2002, p. 81), como se observa abaixo:

\begin{abstract}
Alinho-me, pois, aos defensores das teorias materiais-substanciais da Constituição, porque trabalham com a perspectiva de que a implementação dos direitos fundamentais-sociais (substantivos no texto democrático da Constituição) afigura-se como condição de possibilidade da própria Constituição, naquilo que ela representa de elo conteudístico que une política e direito.
\end{abstract}

O substancialismo foi recepcionado no contexto brasileiro e se envolveu com, pelo menos, dois movimentos nacionais importantes - movimento do direito alternativo e do direito crítico. Esses movimentos entendem que a Constituição é o elemento tendente a transformar o Direito em instrumento de resgate da inclusão social, pois as promessas de um Estado Social nunca teriam sido efetivamente concretizadas em benefício do povo brasileiro (STRECK, 2002, p. 80). Essa vertente do pensamento constitucional se propõe a criar uma alternativa aos avanços da política conservadora, que ameaça as garantias sociais conquistadas, ainda que poucas, durante o período do Estado Social.

Assim, entendo difícil sustentar as teses processuais-procedimentais em países como o Brasil, em que parte considerável dos direitos fundamentais-sociais continua incumprida, passadas mais de duas décadas da promulgação da Constituição. Dito de outro modo: parece muito pouco - mormente se levarmos em conta a pretensão de se construir as bases de um Estado Social no Brasil - destinar ao Poder Judiciário tão somente a função de zelar pelo respeito aos procedimentos democráticos para a formação da opinião e da vontade política, a partir da própria cidadania, como quer, por exemplo, o paradigma procedimental. (STRECK, 2011, p. 83). 
Álvaro Ricardo de Souza Cruz (CRUZ, 2009, p. 8) enxerga nesse pensamento uma característica peculiar do comunitarismo ${ }^{17}$ brasileiro, distinguindo-o do americano. Afirma que o comunitarismo americano está ligado ao Estado por entender que ele tem a tarefa de proteger o modo de vida de uma coletividade que compartilha valores. Já o comunitarismo brasileiro defende uma concepção intervencionista de Estado, sendo esse ente responsável a prestar garantias sociais à população, como enfrentamento a um modelo econômico concentrador de riquezas.

Essa característica fica bem clara a partir do que aponta o professor Streck:

É inexorável que, com a positivação dos direitos sociais-fundamentais, o Poder Judiciário (e, em especial, a justiça constitucional) passe a ter um papel de absoluta relevância, mormente no que pertine à jurisdição constitucional. (STRECK, 2002, p. 141).

Sob outra perspectiva, Luis Werneck Vianna (VIANNA et al, 1999, p. 15), também apontado como pensador substancialista e a quem é atribuída a autoria de tal expressão, considera que o Direito, após a expansão vocacionada do princípio democrático, assume um compromisso social, deixando a Constituição de ser pensada tão só como registro da correlação das forças sociais ou como mero instrumento de controle.

\begin{abstract}
Nesse sentido, a judicialização da política, entre nós, longe de enfraquecer o sistema dos partidos, em especial os da esquerda e da oposição, tende a reforçá-lo, na medida em que propicia - é verdade que no campo predominantemente do direito e dos procedimentos - uma conexão entre a democracia representativa e a participativa, para o que concorrem as ações públicas, em que a cidadania se encontra legitimada para deflagrar o processo judicial contras as instâncias do poder. Tem-se, assim, uma judicialização da política cuja origem está na descoberta, por parte da sociedade civil, da obra do legislador constituinte de 1988, e não nos aparelhos institucionais do Poder Judiciário, como se verá adiante (VIANNA et al, 1999, p. 43).
\end{abstract}

Os direitos sociais representam esse elemento que traz uma característica inovadora e diferenciada ao debate brasileiro sobre a judicialização da política e, em última análise, entre os pensamentos procedimentalistas e substancialistas. Dentro desse espectro, pode-se verificar

$17 \mathrm{O}$ autor afirma que os termos substancialismo, conforme denominação de Vianna, constitucionalismo comunitarista, na senda aberta por Cittadino, e constitucionalismo dirigente, na lição de Bonavides, referem-se ao mesmo fenômeno teórico, isto é, a defesa de que a Constituição, enquanto depósito de valores compartilhados socialmente, é compromissada à defesa das garantias sociais, resgatando as promessas do Welfare State de inclusão social e diminuição das desigualdades. (CRUZ, 2009, p.7). 
certa convergência entre argumentos substancialistas com o pensamento Rawlsiano sobre a jurisdição constitucional. É possível essa comparação se levadas em consideração as funções que assumem o Poder Judiciário dentro do arquétipo democrático imaginado por Rawls: defesa das opções políticas fundamentais e fomento ao uso da razão pública.

Tem-se afirmado, como demonstrado, que o Poder Judiciário assume o compromisso de promover, junto com os outros Poderes, a guarda dos direitos sociais, econômicos e culturais, em virtude de a história política brasileira revelar que os benefícios de um Estado social nunca terem se revertido à favor da população. No contexto nacional, em consonância ao pensamento rawlsiano sobre o mínimo social, elevaram-se os direitos sociais como elementos constitucionais essenciais e, como tais, sua defesa judicial é possível por se revelarem enquanto princípios políticos de justiça básica. Se, no pensamento rawlsiano, o objeto da razão pública são as questões de justiça fundamentais, a proteção dos direitos sociais expande-se também como função do Poder Judiciário, que possui uma argumentação propriamente vinculada a esses elementos.

Ademais, na lição de Rawls, a judicialização da política revela-se como atividade educadora, uma vez que seu exercício fomenta o uso da razão pública nas demais arenas democráticas, expandindo o compromisso com os Princípios de Justiça para as demais instituições. É o que foi salientado pela professora Cecília Lois (LOIS, 2008), ao prestigiar o pensamento de Rawls sobre o papel argumentativo dos elementos constitucionais fundamentais quando a vontade da maioria se opuser a opções políticas de justiça básica.

Com efeito, Vieira demonstra que uma das grandes contribuições de Rawls estaria em afastar o problema da intangibilidade de algumas cláusulas da Constituição, sem precisar recorrer a quaisquer princípios outros que não possam ser justificados racionalmente através da ética e da superioridade dos direitos fundamentais, mas também sem resvalar para um naturalismo. (LOIS, 2008, p. 209).

Até o presente momento, demonstrou-se, neste artigo, o prestígio das teorias substancialistas, especialmente daquelas vinculadas ao modelo deliberativo rawlsiano, na doutrina jurídica brasileira. O substancialismo, enquanto corrente teórica que insere a democracia deliberativa dentro de uma Teoria de Justiça política, foi incorporado no sistema judiciário brasileiro como resposta à crise de efetividade de disposições constitucionais sociais. 
O problema é que as questões que envolvem a eficácia e efetividade de garantias sociais atingem o cenário da política democrática, vale dizer, são anseios sociais que estão sob disputa no cenário político, no campo da representação de interesses legislativos e executivos. Dessa maneira, em última instância, o substancialismo é uma resposta diante de uma observada crise de representatividade que atinge as instituições políticas do Estado.

O Poder Judiciário é apresentado, pelo substancialismo brasileiro, como resposta institucional para problemas que atingem os Poderes políticos. Com base na ideia ralwsiana de formação de uma democracia deliberativa que define opções políticas fundamentais em uma Carta Constitucional, opções essas que estariam a salvo de variações ideológicas, já que representam um consenso sobreposto de doutrinas razoáveis, o Poder Judiciário poderia proteger garantias sociais com base na utilização da razão pública, independentemente da existência ou da ausência de políticas estatais representando esses interesses.

A razão pública, principal elemento para justificar a legitimidade democrática da jurisdição constitucional, está baseada nesse consenso sobreposto de doutrinas razoáveis, cujo conteúdo faz parte do que se chama de disposições constitucionais fundamentais. Todavia, muito se tem questionado, diante das teorias deliberativas, sobre o papel do consenso nas democracias (Pereira, 2012; Mendonça, 2013; Miguel, 2014). John Rawls atribuiu importância crucial à redução dos níveis de conflito na sociedade para a concretização de um plano hígido de democracia. Afinal, o pensador está preocupado em determinar as bases de um contrato social para estabilizar o conflito decorrente do pluralismo, vale dizer, da convivência de diversas doutrinas filosóficas, morais e religiosas que reivindicam, entre si, validade (Rawls, 2005, p. 190).

$\mathrm{Na}$ contramão do consensualismo, aponta-se que a tentativa de se alcançar um consenso na sociedade sobre determinadas regras torna invisíveis os valores normativos que estão agindo sobre essa deliberação para definição de tais ou quais regras, prejudicando doutrinas não hegemônicas ${ }^{18}$ (SANTOS et al, 2004, p. 71). Chantal Mouffe, nas palavras de

\footnotetext{
${ }^{18}$ Tendo por base o pensamento de Laclau e Mouffe, Mendonça (2010) explica que "hegemonia é uma relação em que uma determinada identidade, num determinado contexto histórico-discursivo, de forma precária e contingente, passa a representar, a partir de uma relação equivalencial, múltiplos elementos. A ideia de hegemonia existe justamente em sua relação com a noção de falta constitutiva, presente na teoria do discurso. A falta constitutiva, por sua vez, induz à ideia de que todas as identidades se constituem sempre de forma incompleta, seja em função da própria articulação incompleta de sentidos, seja a partir da relação entre identidades, seja, ainda, por sua negação, a partir de seu corte antagônico (outra identidade que nega sua própria constituição). No sentido de Laclau e Mouffe, portanto, toda identidade vive numa constante busca de sua completude, sendo tal busca, contudo, sempre ineficaz. A hegemonia visa preencher - sempre de forma ineficaz -
} 
Miguel (2014, p. 29), observa que "não é possível falar de um mero consenso em relação a regras e procedimentos, como fazem as teorias liberais em geral, sem observar que tal consenso se estende também aos valores normativos que orientam as regras".

A política democrática - cujo "gesto inaugural", para usar a bela expressão de Claude Lefort, é o "reconhecimento da legitimidade do conflito" (Lefort e Gauchet, 1971, p. 8) - coloca a questão em outro patamar. Há uma norma de reciprocidade, portanto de justiça, quando se reconhece que são legítimas a presença, a discordância e a ação do outro em busca de suas próprias referências. A construção da democracia tanto abraça quanto se contrapõe ao caráter agonístico da luta política. Tal tensão não pode ser eliminada, seja na prática, seja na reflexão teórica, pois a busca de uma democracia isenta do conflito político nega seu próprio caráter democrático. (Miguel, 2011, p. 27).

A intenção de proteger a eficácia de disposições sociais através de mecanismos judiciais pode ser válida, mas representa um grande risco para o diálogo institucional entre os Poderes e, principalmente, um risco para a qualidade democrática do desenvolvimento da política no país. A partir do momento em que se erigem opções políticas fundamentais a salvo de qualquer conflito doutrinário, está-se a negar que o dissenso é próprio da política democrática, provocando um esvaziamento de ações políticas coletivas tendentes a disputar determinados feixes de interesses nos centros públicos. Não só um esvaziamento das ações coletivas, mas legitima a dominação de valores e normas hegemônicas com base na ideia de um consenso moral sobreposto, surgindo um "consenso imposto" (PEREIRA, 2012, p. 72).

A utilização da razão pública, conforme desenvolvida por Rawls, para justificar a legitimidade da jurisdição constitucional, não é solução para os problemas que enfrentam a política democrática brasileira. Não é solução porque as causas que tangenciam a crise de efetividade das disposições constitucionais envolvem muitos outros fatores além do problema da representatividade, fatores que estão sob o cenário de disputa de interesses políticolegislativos.

Nas palavras de Avritzer e Marona (2014, p. 88):

No entanto, o processo de judicialização também implicou a apropriação de fortes prerrogativas soberanas do Congresso em ações que definiram a derrubada da cláusula de barreira, a fidelidade partidária e, mais recentemente, regras da competição eleitoral. Algumas dessas ações ajudaram a organizar o sistema político ao passo que outras contribuíram para a continuidade da sua desorganização.

essa ausência de plenitude. Conforme Laclau: "entendo por 'hegemonia' uma relação em que um conteúdo particular assume, num certo contexto, a função de encarnar uma plenitude ausente" (Ibidem: 122). Daí a ideia de "ordem" hegemônica." (MENDONÇA, 2010, p. 483). 
Entretanto, independentemente do mérito dessas ações, elas implicaram fortes desequilíbrios entre os poderes, que podem afetar a democracia brasileira em um futuro próximo.

Deve ser realçado que a recepção do substancialismo no Brasil indica mais do que uma mera divergência sobre a Teoria de Justiça em que está assentada a atividade da jurisdição constitucional ou sobre a teoria tendente a explicar sua legitimidade democrática. A incorporação do substancialismo no sistema de justiça nacional envolve, sobretudo, a forma como se desenvolve o pensamento jurídico brasileiro em um cenário político-institucional de crise de representatividade, porque, na falta dos outros Poderes executando políticas sociais, o Poder Judiciário teria que assumir essa função perante a população.

Esse cenário indica, logo, que o Poder Judiciário está sustentado em uma Teoria de Justiça liberal que desconsidera o conflito entre políticas e doutrinas razoáveis, erigindo a razão pública como se fosse o próprio véu da ignorância a garantir a imparcialidade de um julgamento. Nesse sistema, os cidadãos somente poderiam reivindicar às instituições aquilo que estivesse abraçado por uma concepção pública de justiça (Rawls, 2000b, p. 64). Ao cabo, essa ideia implica no esvaziamento das arenas políticas e na superlotação dos espaços judiciários para resolução de conflitos que deveriam ser disputados em centros públicos.

Como afirma Miguel (2014, p. 18):

Temos aqui, assim, um bom exemplo da tendência identificada por Nadia Urbinati (2010) em parte do pensamento político contemporâneo, de dissolução do julgamento político, necessariamente parcial, por um tipo de julgamento judicial, portanto orientado por critérios de imparcialidade. Como diz de seus críticos, Rawls "apresenta uma tecnocracia despolitizada. [...] A justiça deve ser determinada em perpetuidade antes do advento do governo e da iniciação da política" (Jackson, 1983 [1980], p. 264).

A proteção de direitos sociais é, assim, o elemento que confere característica especial ao substancialismo brasileiro. Todavia, esse movimento provocou um verdadeiro desgaste na interação democrática entre as instituições de Poder do Estado. As divergências no âmbito teórico ganharam relevância sob a perspectiva prática no cenário politico nacional, à vista da proposta de Emenda Constitucional n. 33 de 2011 (PEC 33), que chegou a ser aprovada pela 
Comissão de Constituição e Justiça (CCJ) da Câmara dos Deputados ${ }^{19}$. A proposta pretendia alterar a quantidade mínima de votos de membros de tribunais para declaração de inconstitucionalidade de leis; condicionar o efeito vinculante de súmulas aprovadas pelo Supremo Tribunal Federal à aprovação pelo Poder Legislativo; e submeter ao Congresso Nacional a decisão sobre a inconstitucionalidade de emendas à Constituição.

A justificativa apresentada no texto da proposta não tem receios de demonstrar um descontentamento do Poder Legislativo com o avanço do Poder Judiciário no controle das questões de mérito político e social. Esclarece o primeiro subscritor da proposta que:

O protagonismo alcançado pelo Poder Judiciário, especialmente dos órgãos de cúpula, é fato notório nos dias atuais. A manifestação desse protagonismo tem ocorrido sob duas vertentes que, embora semelhantes, possuem contornos distintos: a judicialização das relações sociais e o ativismo judicial. (BRASIL, 2011).

Após análise sobre como tem sido a atividade da jurisdição constitucional nos últimos anos em terra brasileira, o primeiro subscritor afirma:

O fato é que, em prejuízo da democracia, a hipertrofia do Poder Judiciário vem deslocando boa parte do debate de questões relevantes do Legislativo para o Judiciário. Disso são exemplos a questão das ações afirmativas baseadas em cotas raciais, a questão das células tronco e tantas outras.

As decisões proferidas nesses casos carecerão de legitimidade democrática porque não passaram pelo exame do Congresso Nacional. Estamos, de fato, diante de um risco para legitimidade democrática em nosso país. (BRASIL, 2011).

Após a submissão da proposta à Câmara, o Deputado João Campos assumiu a relatoria do projeto, elaborando parecer favorável à sua admissibilidade. No relatório, o legislador concluiu que as alterações propostas não violam a cláusula pétrea do Princípio da Separação dos Poderes. Afirma que as alterações pretendem "valorizar a soberania popular, reforçando o comando constitucional previsto no parágrafo único do art.1 da CF” (BRASIL, 2011).

Submetida a proposta à CCJ da Câmara dos Deputados, 64 (sessenta e quatro) deputados emitiram opinião favorável à aprovação da PEC 33/2011 e somente 2 (dois) apresentaram voto em separado pela inadmissibilidade do projeto. A discrepância entre o número de votos indica que há verdadeira intenção de ampla maioria dos membros do Poder

\footnotetext{
${ }^{19}$ A PEC 33, de 2011, está atualmente arquivada em razão do fim de uma legislatura ao cabo do ano de 2014. Todavia, as argumentações utilizadas nos relatórios que serviram de substrato para aprovação da proposta na Comissão de Constituição e Justiça da Câmara dos Deputados são importantes para fins político-científicos.
} 
Legislativo de se opor ao papel ativista que o Poder Judiciário vem assumindo ao longo dos anos no controle de constitucionalidade dos atos políticos.

Não é difícil perceber: mais que mera intenção legislativa de reforma, a PEC 33/2011 revela uma crise institucional entre os Poderes da República. Por detrás dessa proposta está uma tentativa de reformular a relação institucional de controle entre os Poderes Judiciário e Legislativo, atribuindo a este último preponderância na decisão sobre a inconstitucionalidade das leis, em especial das Emendas à Constituição. A reforma pretendeu retirar do Poder Judiciário, em especial do Supremo Tribunal Federal, a prerrogativa de interpretar e dizer a Constituição como orador final, passando tal missão ao próprio Poder Legislativo.

Para além das divergências, e retornando ao enfoque teórico, existe um esforço por parte de projetos jurídicos no Brasil que buscam ampliar a efetividade das disposições constitucionais, principalmente daquelas relacionadas aos direitos e às garantias sociais. Contudo, um ativismo no exercício da jurisdição constitucional não é a resposta para esses problemas que atingem a efetividade das disposições sociais fundamentais, simplesmente porque isso envolve causas e gera consequências nas bases da política democrática.

Não se nega a contribuição positiva de decisões judicias de natureza política para o cenário de avanços de direitos sociais e individuais, como o caso dos medicamentos para pessoas portadoras do vírus HIV ou o caso do casamento entre casais homoafetivos (AVRITZER e MARONA, 2014). Todavia, no mesmo passo que o substancialismo contribuiu para avançar na conquista de mais direitos, pode-se dizer que ele reforçou uma crise de diálogo entre instituições igualmente importantes para o desenvolvimento da política democrática.

\section{CONCLUSÃO}

O avanço contemporâneo da literatura política tem caminhado na busca de elementos para fortalecer e radicalizar a democracia. Nessa trilha, o Direito participa como agente protagonista em algumas conquistas, seja pela positivação de garantias fundamentais, seja pela proteção desses elementos por iniciativa jurisdicional.

Contudo, muito se tem discutido sobre a função da jurisdição constitucional nesse sistema, principalmente a partir do fortalecimento de teorias democráticas que realçam o papel da deliberação pública na definição de decisões políticas importantes. Como visto, John 


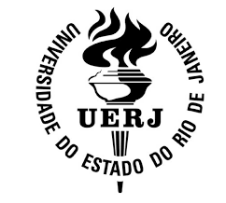

Rawls desenvolveu uma Teoria de Justiça na qual o Poder Judiciário assume papel de relevância no sistema político ao ser responsável por proteger as disposições constitucionais fundamentais. O conteúdo dessas disposições seria definido em um momento político apriorístico, o que destaca a formação de um consenso sobre esses elementos que estariam salvaguardados pela Constituição.

Esse consenso sobre os princípios de justiça fundamentais à comunidade política estaria protegido por limites sobrepostos ao pluralismo de doutrinas filosóficas, morais e religiosas existentes na sociedade. Isso significa que maiorias políticas ocasionais não têm legitimidade para alterar o conteúdo desses princípios de justiça, já que foram definidos como essenciais em circunstâncias de imparcialidade.

Nesse esquema, a jurisdição constitucional teria legitimidade para proteger essas disposições constitucionais fundamentais porque estaria baseada na utilização da razão pública como elemento discursivo institucional. Para Rawls, a razão pública garante a legitimidade democrática da atividade jurisdicional porque seu conteúdo se espelha nos próprios princípios de justiça a que visa proteger, princípios esses que formam o consenso sobreposto.

O arranjo institucional desenhado por Rawls exerceu grande influência no desenvolvimento teórico da doutrina substancialista brasileira. No contexto nacional, o substancialismo foi incorporado no sistema jurídico em decorrência de circunstâncias políticas especiais, que alguns autores denominam de comunitarismo brasileiro, movimento que defende uma concepção intervencionista de Estado, responsável por prestar garantias sociais à população. A principal justificativa é a constatação de que os direitos sociais, no contexto nacional, carecem de proteção por parte dos outros Poderes do Estado.

O grande elemento responsável por essa incorporação do substancialismo no sistema brasileiro advém, pois, de uma desconfiança no desenvolvimento institucional de políticas sociais. Contudo, a atividade jurisdicional não deve ser utilizada como solução para os problemas que passa o sistema político brasileiro, problemas relacionados à crise de representatividade das instituições políticas. Não é solução porque as causas que tangenciam a crise de efetividade das disposições constitucionais envolvem muitos outros fatores além do problema da representatividade, fatores que estão sob o cenário de disputa de interesses político-legislativos. 
O ativismo judicial, longe de ser a solução, intensificou o cenário de crise entre os Poderes estatais. É o que revela a aprovação do Projeto de Emenda Constitucional no 33 de 2011 na Comissão de Constituição e Justiça da Câmara dos Deputados, na qual o Poder Legislativo questiona exatamente a legitimidade democrática do Poder Judiciário. Distanciando-se do mérito da questão, o projeto revela o aprofundamento dos problemas de diálogo entre os Poderes, que são igualmente importantes para a radicalização de políticas democráticas.

Por isso, esse ativismo judicial na definição de ações estatais representa um grande risco para a qualidade democrática, no cenário do desenvolvimento da política no Brasil, especialmente porque desconsidera a necessidade de um diálogo entre instituições para a definição de medidas públicas que geram efeitos macroeconômicos. Considera-se relevante um alinhamento entre Direito e Política para a densificação do sistema democrático, mas os pressupostos que embasam a atividade da jurisdição constitucional no Brasil devem ser repensados para se construir um modelo de justiça capaz de contribuir para o fortalecimento da democracia.

\section{REFERÊNCIAS}

AVRITZER, Leonardo; MARONA, Marjorie Corrêa. Judicialização da Política no Brasil: ver além do constitucionalismo liberal para ver melhor. Revista Brasileira de Ciência Política, n 15 . Brasília, Setembro-dezembro de 2014, pp. 69-94.

BARROSO, Luís Roberto de. Curso de Direito Constitucional Contemporâneo. 2.ed. São Paulo: Saraiva, 2010.

BRASIL. Câmara dos Deputados. Proposta de Emenda à Constituição 33, de 2011. Ementa: Altera a quantidade mínima de votos de membros de tribunais para declaração de inconstitucionalidade de leis; condiciona o efeito vinculante de súmulas aprovadas pelo Supremo Tribunal Federal à aprovação pelo Poder Legislativo e submete ao Congresso Nacional a decisão sobre a inconstitucionalidade de Emendas à Constituição. Disponível em: $<$ http://www.camara.gov.br/proposicoesWeb/prop_mostrarintegra?codteor=876817\&filename $=$ Tramitacao-PEC+33/2011>. Acesso em: 15 maio 2016.

CRUZ, Álvaro Ricardo de Souza. Uma Nova Alternativa para o Direito Brasileiro: O Procedimentalismo. In: SARMENTO, Daniel. (Org.). Filosofia e Teoria Constitucional Contemporânea. Rio de Janeiro: Lumen Juris, 2009. 
LOIS, Cecília Caballero. O constitucionalismo de John Rawls: elementos para a sua configuração. Revista da Faculdade de Direito - UFPR, Curitiba, n. 48, pp. 203-218, 2008.

MENDONÇA, Daniel de. Teorizando o agonismo: crítica a um modelo incompleto. Sociedade e Estado, v.25, n.3, pp. 479-97, 2010.

MENDONÇA, Ricardo Fabrino. Teoria Crítica e Democracia Deliberativa: diálogos instáveis. Opinião Pública, Campinas, vol. 19, nº1, p. 49-64, 2013.

MIGUEL, Luis Felipe. Representação democrática: autonomia e interesse ou identidade e advocacy. Revista Lua Nova, São Paulo, 84: 25-63, 2011.

Consenso e Conflito na Teoria Democrática: Para Além do “Agonismo". Revista Lua Nova, São Paulo, 92: 13-43, 2014.

OLIVEIRA, Marcelo Andrade Cattoni de. Um ensaio sobre o Liberalismo Político de John Rawls: Construtivismo Político e Razão Pública. Revista de Direitos e Garantias Fundamentais. Vitória, n. 7, p. 81-96, jan./jun. 2010.

Republicanismo e Liberalismo: da relação entre constitucionalismo e democracia no marco das tradições do pensamento político moderno. Virtuajus, Belo Horizonte, v.2, 2003.

PEREIRA, Marcus Abílio. Movimentos Sociais e Democracia: a tensão necessária. Opinião Pública, Campinas, vol.18, nº1, Junho, 2012, p. 68-87.

RAWLS, John. Uma Teoria da Justiça. Trad: Almiro Pisetta e Lenita. São Paulo: Martins Fontes, 2000a.

Ática, 2000b.

O Liberalismo Político. Trad. Dinah de Abreu Azevedo. 2.ed. São Paulo: Editora

RODAS, Francisco Cortes; SOLÓRZANO, Alfonso Monsalve (Orgs.). Liberalismo y Comunitarismo: Derechos Humanos y Democracia. Espanha: Edicions Alfons el Magnanim, 1996.

SANTOS, Boaventura de Sousa; MENESES, Maria Paula; NUNES, João Arriscado. Introdução: para ampliar o cânone da ciência: a diversidade epistemológica do mundo. In: SANTOS, Boaventura de Sousa. Semear outras soluções: os caminhos da biodiversidade e dos conhecimentos rivais. Porto: Edições Afrontamento, p. 19-101, 2004.

SOUZA NETO, Cláudio Pereira de. Teoria Constitucional e Democracia Deliberativa: um estudo sobre o papel do direito na garantia das condições para a cooperação na deliberação democrática. Rio de Janeiro: Renovar, 2006.

STRECK, Lênio Luiz. Jurisdição Constitucional e Hermenêutica: uma nova crítica ao Direito. Porto Alegre: Livraria do Advogado, 2002. 
Verdade e Consenso: Constituição, Verdade e Teorias Discursivas. 4. ed. São Paulo: Saraiva, 2011.

VIANNA, Luiz Werneck; CARVALHO, Maria Alice Resende; MELO, Manuel Palacios C.; BARGOS, Marcelo B. A judicialização da política e das relações sociais no Brasil. Rio de Janeiro: Revan, 1999. 